\title{
Mathematical model for assessing the high-rise apartment buildings complex quality
}

\author{
Azariy Lapidus ${ }^{1}$, and Yana Shesterikova ${ }^{1, *}$ \\ ${ }^{1}$ Moscow State University of Civil Engineering, Yaroslavskoye sh., 26, 129337 Moscow, Russia
}

\begin{abstract}
With use of factor matrix, four groups of parameters were identified, and one group was determined as the most significant one, which affects the complex quality index in high-rise apartment buildings constriction. The dependence between the complex quality index and the values of influencing factors was determined. The mathematical model that allows making adjustments to achieve the required levels of quality at all stages of the construction project was considered.
\end{abstract}

\section{Introduction}

High-rise apartment buildings take a very significant place in the practice of world housing construction. The problem of quality improvement should be considered comprehensively, taking into account the main factors affecting the quality of construction of the facility as a whole [1-2]. The authors proposed to consider the complex quality indicator from the standpoint of system engineering, as a set of individual factors affecting the quality of a construction facility, and the integrated potential of a complex quality indicator in construction is used as its assessment [3-5].

\section{Materials and Methods}

It should be noted that the authors developed a version of the questionnaire to obtain the initial values. Experts were asked to evaluate in conditional balls from 0 to 100 the value of a high-rise apartment buildings complex quality index for each variant of combinations of coded values of 4 factors main groups which are presented in the table.

The experts were reputable professionals who have many years of professional experience and are the heads of construction structures working in the field of capital repairs at the present time. With the help of expert research, the most significant eight parameters that affect the quality of a building facility by more than $90 \%$ are determined:

To assess the quality of construction with their various combinations, it is necessary to construct 26244 objects. In further studies, the authors compiled matrix of intercorrelations for the selected parameters. Further, four groups of well-interconnected variables (z1, z2, z3, z4) were pointed out, after which these groups of variables were presented in the form of columns, and the factors in the form of rows.

\footnotetext{
*Corresponding author: shesterikova.jana@yandex.ru
} 
Table 1. Coded Factor Values.

\begin{tabular}{|c|c|c|c|c|c|}
\hline & \multicolumn{2}{|l|}{ Factors } & \multicolumn{3}{|c|}{ Levels of variation factors } \\
\hline $\mathrm{No}$ & Natural form & Code & -1 & 0 & +1 \\
\hline 1. & $\begin{array}{c}\text { development plan for a land plot } \\
\text { and the full volume of materials, } \\
\text { including all sections on engineering } \\
\text { surveys }\end{array}$ & $\mathrm{Z}_{1}$ & $\begin{array}{l}\text { the absence of } \\
\text { most of the } \\
\text { elements and } \\
\text { incomplete }\end{array}$ & $\begin{array}{c}\text { absence of } \\
\text { separate elements } \\
\text { and separate } \\
\text { reports }\end{array}$ & $\begin{array}{l}\text { the presence of } \\
\text { all elements } \\
\text { and the full } \\
\text { scope of } \\
\text { materials }\end{array}$ \\
\hline 2. & $\begin{array}{l}\text { Technical conditions for all objects, } \\
\text { compliance with design solutions to } \\
\text { the requirements of Code of Rules, } \\
\text { the standard GOST and other } \\
\text { regulatory and technical documents } \\
\text { in force at the time of the } \\
\text { examination }\end{array}$ & $\mathrm{Z} 2$ & $\begin{array}{l}\text { The absence and } \\
\text { mismatch }\end{array}$ & $\begin{array}{l}\text { partially presence } \\
\text { and partial } \\
\text { compliance with } \\
\text { requirements }\end{array}$ & $\begin{array}{c}\text { presence and } \\
\text { full compliance } \\
\text { with } \\
\text { requirements }\end{array}$ \\
\hline 3. & $\begin{array}{c}\text { qualification structure, including } \\
\text { specialists with work experience and } \\
\text { an appropriate level of qualification, } \\
\text { the observance of external } \\
\text { conditions and modes of operation }\end{array}$ & Z3 & $\begin{array}{c}\text { low qualification } \\
\text { of most } \\
\text { specialists } \\
\text { not available }\end{array}$ & $\begin{array}{l}\text { the average level } \\
\text { of qualification of } \\
\text { the majority of } \\
\text { specialists } \\
\text { notinfull }\end{array}$ & $\begin{array}{c}\text { the high level } \\
\text { of qualification } \\
\text { of the majority } \\
\text { of specialists } \\
\text { available }\end{array}$ \\
\hline 4. & $\begin{array}{c}\text { the sequence of work; availability of } \\
\text { acts of input of separate systems and } \\
\text { equipment, acts of hidden work }\end{array}$ & $\begin{array}{ll}\mathrm{Z} \\
\mathrm{f} 4\end{array}$ & $\begin{array}{l}\text { not complied, } \\
\text { not available }\end{array}$ & $\begin{array}{r}\text { partiallycomplied } \\
\text { notfull }\end{array}$ & $\begin{array}{c}\text { Complied } \\
\text { Not available }\end{array}$ \\
\hline
\end{tabular}

Moreover, each group in the row corresponds to the average value of the correlation coefficient of the corresponding factors for this group. Thus, a factor matrix was done.

Further, using the regression equations, which allow approximating the experimental data with regard to statistical parameters, it is able to determine the dependence between the complex quality index and the values of the influencing factors $\mathrm{z1}, \mathrm{z2}, \mathrm{z3}, \mathrm{z} 4[7,8,13,14]$. .

The task of regression analysis is the selection of mathematical formulas, that is the best way to describe the experimental data. As a regression model, we will use a linear regression model, where we will select the already received factor group z1 z2 z3 and z4, as well as the constant factor. The second model that we consider is a quadratic model, where also the factors are the groups of factors $\mathrm{z} 1 \mathrm{z} 2 \mathrm{z} 3$ and z4, their squares and the constant factor. The third model we consider is a cubic model, where we choose 13 factors, exactly the groups $z 1$ $\mathrm{z} 2 \mathrm{z} 3 \mathrm{z} 4$, their squares and their cubes, as well as a constant feature.

After applying the regression model, we will see that a fairly good quality of the approximation (the coefficient of determination $\mathrm{R}^{2}$ is equal to 0.754 ) is achieved already on the linear model.

$$
\begin{gathered}
y=c+a_{1} z_{1}+\ldots .+a_{4} z_{4}+e \\
y=c+a_{1} z_{1}+\ldots .+a_{4} z_{4}+a_{5}\left(z_{1}\right)^{2}+\ldots . a_{8}\left(z_{4}\right)^{2}+e \\
y=c+a_{1} z_{1}+\ldots . . a_{4} z_{4}+a_{5}\left(z_{1}\right)^{2}+\ldots . . a_{8}\left(z_{4}\right)^{2}+a_{9}\left(z_{1}\right)^{3}+\ldots \ldots . a_{12}\left(z_{4}\right)^{3}+e
\end{gathered}
$$

The model does not include factors which are responsible for pairwise interactions between factors for the following reasons:

- these factors will be well explained by the original factors, so adding them to the matrix of factors will worsen the predictive power of the model, in particular, the dispersion of predictions will increase significantly due to the peculiarities of the output in the regression analysis. 
- adding these features the coefficient of determination of the quadratic model does not show a significant increase in the quality of the model, therefore adding these features is not justified.

There is a formula for coefficients estimation of the regression model in general:

$\mathrm{Y}=\mathrm{z}^{*} \mathrm{a}+\mathrm{e} \quad$ (4)

Y- size vector 250 - expert evaluations

$\mathrm{Z}$ - size matrix $250 * 5$ in the case of a linear model, size matrix $250 * 9$ in the case of a quadratic model and size matrix $250 * 13$ in the case of a quadratic model.

a - vector of parameters of the regression model which has a size of 5 in the case of a linear model, 9 in the case of a quadratic model, 13 in the case of a cubic model.

$\mathrm{e}-\mathrm{a}$ dimension vector, 250 is a regression model error.

Recall, the coefficient of determination is calculated by the following formula:

$$
\begin{gathered}
R^{2}=1-\frac{\sum_{\mathrm{i}=1}^{250}\left(\mathrm{y}_{\mathrm{i}}-\widehat{\mathrm{y}_{1}}\right)^{2}}{\sum_{\mathrm{i}=1}^{250}\left(\mathrm{y}_{\mathrm{i}}-\overline{\mathrm{y}}\right)^{2}} \\
\widehat{\mathrm{y}_{1}}=\widehat{\mathrm{c}}+\widehat{\mathrm{a}} z 1_{\mathrm{i}}+\widehat{\mathrm{a}_{2}} z 2_{\mathrm{i}}+\widehat{\mathrm{a}_{3}} z 3_{\mathrm{i}}+\widehat{\mathrm{a}_{4}} z 4_{\mathrm{i}} \\
\bar{y}=\frac{1}{250} \sum_{\mathrm{i}=1}^{250} \mathrm{y}_{\mathrm{i}}
\end{gathered}
$$

$\widehat{c}, \widehat{a_{1}}, \widehat{a_{2}}, \widehat{a_{3}}, \widehat{a_{4}}-$ parameter estimation $c, a_{1}, a_{2}, a_{3}, a_{4}$ - evaluation by the method of least squares

Evaluation of the parameters vector will be determined by the classical least squares method. It is known that this method allows to find the best estimate of the parameters vector from the minimum of the variance point of view.

Evaluation can be found by the following formula:

$a^{\wedge}=\left(z^{\mathrm{T}} \mathrm{z}\right)^{-1} \mathrm{z}^{\mathrm{T}} \mathrm{Y}(8)$

$\mathrm{z}^{\mathrm{T}}-$ transposed matrix

$\left(z^{T} z\right)^{-1}$ - inverse matrix for the matrix $z^{T} z$.

We received the following models:

\section{Linear model}

$\mathrm{Y}=59.8+1.97 *\left(\mathrm{z}_{1}\right)+8.03 *\left(\mathrm{z}_{2}\right)+8.22 *\left(\mathrm{z}_{3}\right)+4.89 *\left(\mathrm{z}_{4}\right)$. The coefficient of determination (ie, the quality of the approximation) of the model is 0.754 . The closer the coefficient of determination to 1 , the better the model approximates the data.

2. Quadratic model

$\mathrm{Y}=57.95+1.97 *\left(\mathrm{z}_{1}\right)+8.03 *\left(\mathrm{z}_{2}\right)+8.22 *\left(\mathrm{z}_{3}\right)+4.89 *\left(\mathrm{z}_{4}\right)+9.14 *\left(\mathrm{z}_{1}\right)^{2}-6.36 *\left(\mathrm{z}_{2}\right)^{2}-$ $4.61 *\left(z_{3}\right)^{2}+4.39 *\left(z_{4}\right)^{2}$.

The coefficient of determination of the model is 0.845 .

\section{Cubicmodel}

$\mathrm{Y}=57.95+1.97 *\left(\mathrm{z}_{1}\right)+8.03 *\left(\mathrm{z}_{2}\right)+8.22 *\left(\mathrm{z}_{3}\right)+4.89 *\left(\mathrm{z}_{4}\right)+9.14 *\left(\mathrm{z}_{1}\right)^{2}-6.36 *\left(\mathrm{z}_{2}\right)^{2}-$ $4.61 *\left(z_{3}\right)^{2}+4.39 *\left(z_{4}\right)^{2}+0.00 *\left(z_{1}\right)^{3}+0.00 *\left(z_{2}\right)^{3}+0.00 *\left(z_{3}\right)^{3}+0.00 *\left(z_{4}\right)^{3}$.

The coefficient of determination of the model is 0.845 .

It can be noted that the coefficients in the cubic model with the factors $z_{1}{ }^{3}, z_{2}{ }^{3}, z_{3}{ }^{3}$ and $z_{4}{ }^{3}$ turned out to be 0 and the quality of the cubic model from the point of view of the coefficient of determination compared to the quadratic model remained the same. This is easy to explain because the values of $z_{1}^{3}$ coincide with the corresponding values of $z_{1}$. Indeed, 1 in a cube is 1,0 in a cube is $0,-1^{3}$ is -1 . The same is true for features $z_{2}, z_{3}$ and $z_{4}$.

Thus, the use of the cubic model in this case does not increase the quality of the prediction compared to the quadratic model.

Because the true nature of the investigated dependence is not always known, for practical purposes, it is sufficient to know its approximate expression. 


\section{Results}

Based on conducted research, we can conclude that the most convenient form of a mathematical model in performing regression analysis calculations is an equation in the form of a second-order polynomial. This is due to the fact that second-order polynomial models are easy to systematize and study for an extremum, which makes it possible to study in detail regions of optimum and sections of response surface with significant curvature, where the usual linear model becomes inadequate.

Moreover, the number of experiments $\mathrm{N}$ must not be less than the number of coefficients to be determined.

\section{Conclusions}

In modern conditions, the most important thing is to consider the problems of providing quality systemically. In this approach to the labor results, the following stages are distinguished: the transfer of the process quality to the quality of the labor result, the consideration of the quality of the product creation process, as a complex of sequential operations, which together form its quality. For this purpose the method of generalized (integral) evaluation is ideally suited, which is the basis of such science as "qualimetry",the founder of which was Professor G. G. Azgaldov, and J. Van Ettinger and George Setting. worked on the development of this science abroad.

The absence of complex indicators and criteria for assessing the progressiveness is the most significant methodological short of the methods used in construction.

The use of a mathematical model that ultimately reflects the essence of considering phenomenon is the optimal solution for successful prediction and assessment of the factors influence on the complex quality index potential.

\section{References}

1. A.A. Borovkov, Mathematical statistics. Parameter estimation (Hypothesis Testing, 2010)

2. A.A. Gusakov, U.M. Bogomolov, A.I. Brekhman, G.A. Vagonyan, Systems engineering construction (Publishing house ACB, 2004)

3. A.A. Lapidus, A.U. Beregniy, Building materials, equipment, technologies of the XXI century 11, 4-5 (2010)

4. A.A. Lapidus, Y.V. Shesterikova, Modern science and innovations 3, 74-80 (2017)

5. A.A. Lapidus, A.U. Beregniy, Vestnik MGSU 2, 30-33 (2012)

6. A.I. Kobzar, Applied mathematical statistics. For engineers and scientists (FIZMATLIT, Moscow, 2006)

7. A.A. Lapidus, A.U. Beregniy Vestnik MGSU 3, 30-33 (2012)

8. A. Lapidus, I. Abramov, E3S Web of Conferences, 33, 03066 (2018)

9. Kh.L.-A Saydayev, PhD Thesis (Moscow, 2012)

10. J.T.L. Ooi, T.T.T. Le, N.-J. Lee, Journal of Housing Economics 26, 126-138 (2014)

11. P. de Wilde, D. Coley, Building and Environment 55, 1-7 (2012)

12. V.V. Efimov, Statistical methods in quality management, (U1STU, Ulyanovsk, 2003)

13. D.V. Topchy, PhD Thesis (Moscow, 2015)

14. T.M. Froese, Automation in Construction 19-5, 531-538 (2010) 